\title{
Androgen-regulated genes differentially modulated by the androgen receptor coactivator L-dopa decarboxylase in human prostate cancer cells
}

\author{
Katia Margiotti ${ }^{\dagger 2,3}$, Latif A Wafa ${ }^{\dagger 1,2}$, Helen Cheng2, Giuseppe Novelli³, \\ Colleen C Nelson ${ }^{1,2}$ and Paul S Rennie*1,2
}

Address: ${ }^{1}$ Department of Pathology and Laboratory Medicine, Faculty of Medicine, University of British Columbia, Vancouver, BC, V6T 2B5, Canada, 2The Prostate Centre at Vancouver General Hospital, 2660 Oak Street, V6H 3Z6, Vancouver, BC, Canada and ${ }^{3}$ Department of Biopathology and Diagnostic Imaging, Tor Vergata University of Rome, Viale Oxford, 81-00133, Rome, Italy

Email: Katia Margiotti - katia.margiotti@vch.ca; Latif A Wafa - latif@interchange.ubc.ca; Helen Cheng - helen.cheng@vch.ca; Giuseppe Novelli - novelli@med.uniroma2.it; Colleen C Nelson - colleen.nelson@ubc.ca; Paul S Rennie* - prennie@interchange.ubc.ca

* Corresponding author †Equal contributors

Published: 6 June 2007

Molecular Cancer 2007, 6:38 doi:10.1186/1476-4598-6-38
Received: 27 March 2007

Accepted: 6 June 2007

This article is available from: http://www.molecular-cancer.com/content/6/1/38

(c) 2007 Margiotti et al; licensee BioMed Central Ltd.

This is an Open Access article distributed under the terms of the Creative Commons Attribution License (http://creativecommons.org/licenses/by/2.0), which permits unrestricted use, distribution, and reproduction in any medium, provided the original work is properly cited.

\begin{abstract}
Background: The androgen receptor is a ligand-induced transcriptional factor, which plays an important role in normal development of the prostate as well as in the progression of prostate cancer to a hormone refractory state. We previously reported the identification of a novel AR coactivator protein, L-dopa decarboxylase (DDC), which can act at the cytoplasmic level to enhance AR activity. We have also shown that DDC is a neuroendocrine (NE) marker of prostate cancer and that its expression is increased after hormone-ablation therapy and progression to androgen independence. In the present study, we generated tetracycline-inducible LNCaP-DDC prostate cancer stable cells to identify DDC downstream target genes by oligonucleotide microarray analysis.
\end{abstract}

Results: Comparison of induced DDC overexpressing cells versus non-induced control cell lines revealed a number of changes in the expression of androgen-regulated transcripts encoding proteins with a variety of molecular functions, including signal transduction, binding and catalytic activities. There were a total of 35 differentially expressed genes, 25 up-regulated and 10 downregulated, in the DDC overexpressing cell line. In particular, we found a well-known androgen induced gene, TMEPAl, which wasup-regulated in DDC overexpressing cells, supporting its known co-activation function. In addition, DDC also further augmented the transcriptional repression function of AR for a subset of androgen-repressed genes. Changes in cellular gene transcription detected by microarray analysis were confirmed for selected genes by quantitative real-time RTPCR.

Conclusion: Taken together, our results provide evidence for linking DDC action with AR signaling, which may be important for orchestrating molecular changes responsible for prostate cancer progression. 


\section{Background}

Prostate cancer is the most commonly diagnosed invasive male cancer in North America and in other Western countries [1]. In most cases prostate cancer begins as an androgen-dependent tumor that undergoes clinical regression in response to pharmacological and surgical strategies that reduce testosterone concentration. This form of therapy is generally used to treat advanced cancer or those that recur after radiation or surgical procedures to remove the primary cancer. Despite androgen withdrawal therapy most patients develop lethal androgen-independent (AI) tumors [2,3]. At present, no effective therapy is available for this latter group of patients [4]. The underlying molecular mechanism involved in androgen-independent prostate cancer and the therapies aimed at this are the active areas of current research.

The actions of androgen within the prostate are mediated by the androgen receptor (AR), a member of the nuclear receptor family of ligand-activated transcription factors [5]. Upon binding hormone, AR binds to androgen response elements in androgen receptor-responsive promoters, recruits multiple coregulators, and activates transcription of androgen-regulated genes involved in cell growth and survival $[4,6,7]$. In the majority of AI tumors, AR continues to be expressed and seems to be activated under androgen-depleted conditions [8]. Alterations in AR or the AR signaling pathway are potential explanations for progression to androgen independence $[9,10]$. A large number of coactivators and corepressors involved in the regulation of AR-driven transcription have been identified [11]. They function as signaling intermediaries between AR and general transcriptional machinery. Furthermore, an increase in coactivator levels has been shown in AI disease [12-16]. Coactivator proteins have been shown to enhance the activity of AR through a variety of mechanisms, including use of alternative ligands, sensitization of the receptor to lower levels of androgens, and ligandindependent activation $[14,17]$.

Using the repressed transactivator (RTA) yeast two-hybrid system, we previously identified a novel AR-coactivator protein, L-dopa decarboxylase (DDC) [18], also referred to as aromatic L-amino acid decarboxylase (AADC). DDC is responsible for decarboxylating both L-dopa and L-5hydroxytryptophan into dopamine and serotonin, respectively [19]. The human gene encoding the L-dopa decarboxylase enzyme, referred to as DDC, maps to chromosome band 7p11 and is composed of 15 exons spread out over at least $85 \mathrm{~kb}$ of genomic DNA [20]. DDC is widely distributed in neural tissues, where it plays a neuron-specific role as a neurotransmitter biosynthetic enzyme, and in non-neuronal tissues (adrenals, kidney, liver, gastrointestinal tract and lungs), where it acts as a non-specific decarboxylating enzyme and may have other undetermined functions [21]. Our recent studies using tissue microarrays and dual immunofluoresence indicate that in prostate cancer, DDC is not only a neuroendocrine (NE) marker, but is also co-expressed with AR in a subset of NE tumor cells [22]. DDC-positive prostate cancer cells show a dramatic increase in number after extended periods of neoadjuvant hormone withdrawal ( $>6$ months) and in metastatic tumors that have progressed to the AI phenotype [22]. The enhancement of AR transactivation by DDC is likely restricted to the AR-positive subset of NE cells. The mechanism of DDC-mediated regulation of AR signaling in prostate carcinogenesis remains unknown, but may involve sensitization of AR to limiting concentration of androgen [18].

In the past few years, newly developed technologies such as gene microarrays [23] have enabled the determination of molecular differences between normal and transformed cells at the genome wide-level. Microarrays have been used to study androgen regulated genes involved in the development of prostate cancer [24], and to characterize molecular function of AR or other steroid receptor interacting proteins [25-27]. In particular, microarray analysis has been used to better define the molecular function of Ebp1 protein, an AR corepressor [25], and to study AIB1 protein, a steroid receptor coactivator [27], as well as to characterize a novel modulator of AR activity, the male germ cell-associated kinase (MAK) [26]. These studies suggest that microarray analysis is a useful means for studying the effects on gene expression of steroid receptor interacting proteins. Here, in an effort to better understand the molecular function of DDC as a coactivator of AR-mediated signaling and to identify novel targets of prostate carcinogenesis, we evaluated the effects of regulated DDC expression in an inducible manner in LNCaP cells using gene microarray analysis.

\section{Results \\ Inducible expression of DDC in LNCaP human prostate cancer cells}

The identification of AR-regulated genes that are affected by DDC overexpression may provide important clues regarding the biology of this catecholamine synthesis enzyme and its influence on AR function. Toward this end, the change in gene expression of androgen-regulated genes caused by sustained DDC overexpression were analyzed in vitro by the generation of LNCaP cells stably expressing Dox-inducible DDC. We used human androgen-dependent prostate cancer cells (LNCaP), since our primary goal was to assess the co-activation function of DDC, known to enhance AR activity through an androgen-dependent mechanism [18]. To verify the effects of Dox treatment on expression of the DDC gene, LNCaP cells, stably expressing Dox-inducible DDC (LNCaPDDC) or the vector control (LNCaP-pDEST) were treated 
for 48 hours under mock-induced (-Dox) and Doxinduced (+Dox) conditions. With Dox treatment, we observed an optimal 6-fold increase in DDC protein levels when compared with mock-induced (-Dox) LNCaP-DDC cells. No detectable DDC protein was found under the Dox-induced (+Dox) or mock-induced (-Dox) condition in the LNCaP-pDEST cell line, confirming the fact that endogenous DDC protein expression levels in this cell line are below detection when directly compared to ectopic overexpression (Figure 1A) [18]. To investigate the extent of DDC overexpression at the RNA level, we compared by RT-PCR the mRNA levels in DDC overexpressing cells, with the vector control cells after Dox stimulation. In the LNCaP-DDC cells, higher levels of DDC mRNA were observed than in the vector control LNCaP-pDEST cells, where only a faint band was detected (Figure 1B).

\section{Influence of DDC on the androgen-regulated gene expression profile}

The availability of the LNCaP-DDC cell line afforded us an opportunity to study the influence of DDC overexpression on global gene expression using the Human Operon $21 \mathrm{~K}$ oligonucleotide array. Our goal in this study was to identify which genes among the AR-regulated genes, are affected by DDC overexpression. We prepared total RNA from DDC overexpressing cells (LNCaP-DDC) and from the LNCaP control cell lines (LNCaP-DDC-Dox, LNCaPpDEST- Dox, and LNCaP-pDEST+Dox) after 48 h treat- ment with or without Dox, 24 h of which was in the presence or absence of R1881 synthetic hormone (Figure 2). Independent probe synthesis from different batches of RNA and hybridizations were performed in duplicate. To account for dye bias a dye swap was also performed. To identify the androgen-regulated genes in both LNCaPDDC and LNCaP control cells, total RNA isolated from hormone treated (+R1881) samples was combined with total RNA isolated from hormone-untreated (-R1881) samples and the relative abundance of each gene was calculated as a ratio between hormone-treated and hormone-untreated samples. The data set was normalized, and a filter was applied to select only those genes whose expression level was significant $(p \leq 0.05)$ in at least 1 out of the 2 conditions. A total of 3,127 genes were identified, and presented as a scatter correlation plot in Figure 3.

Genes that showed significant expression levels across cell types $(p \leq 0.05)$ were further analyzed to characterize those genes whose expression levels were increased or repressed by at least 2 -fold during hormone treatment $( \pm$ R1881). Genes showing an expression level $>0.5$ and $<2$ were classified as unchanged and not considered further. In this study, we focused on those genes that were hormone up-or down-regulated in both LNCaP-DDC and LNCaP control cells.

A

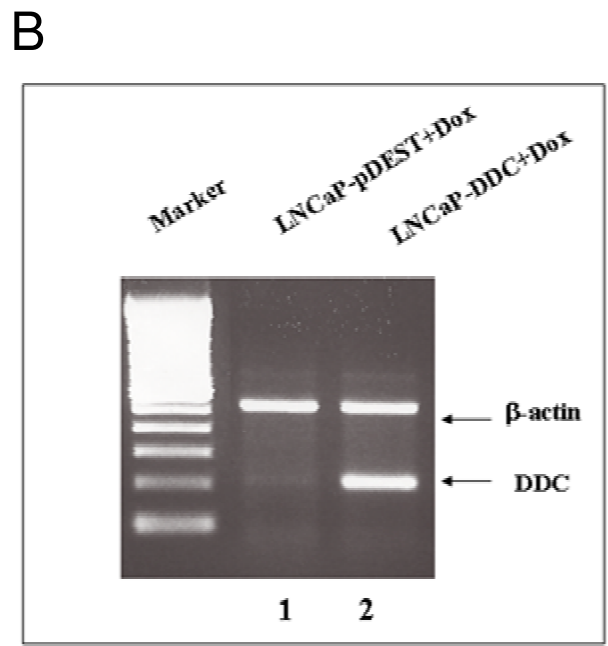

Figure I

LNCaP-DDC cell line displays regulated DDC expression with Dox treatment. Shown are the results from (A) Western blot and (B) semiquantitative RT-PCR analysis of the expression of DDC protein and mRNA, respectively. In A, LNCaP-DDC and LNCaP-pDEST (vector control) cells were treated for 48 hours under mock-induced (-Dox) and Doxinduced (+Dox) conditions before protein lysate preparation. No visible expression was detected in the LNCaP-pDEST control cells regardless of Dox treatment status (lines 3-4). A 6 fold increased DDC expression level was detected in the Doxinduced LNCaP-DDC cells compared to the mock-induced cells (lines I-2), after $\beta$-actin normalization. In B, total cellular RNA was isolated from LNCaP-DDC and LNCaP-pDEST cells after 48 hours of Dox treatment. After reverse transcription, PCR was performed with DDC and $\beta$-actin specific primers. The up-regulation of the 209-bp DDC-specific band was detected in LNCaP-DDC cells (line 2). A 100 bp DNA ladder (Promega) was used for size markers. 


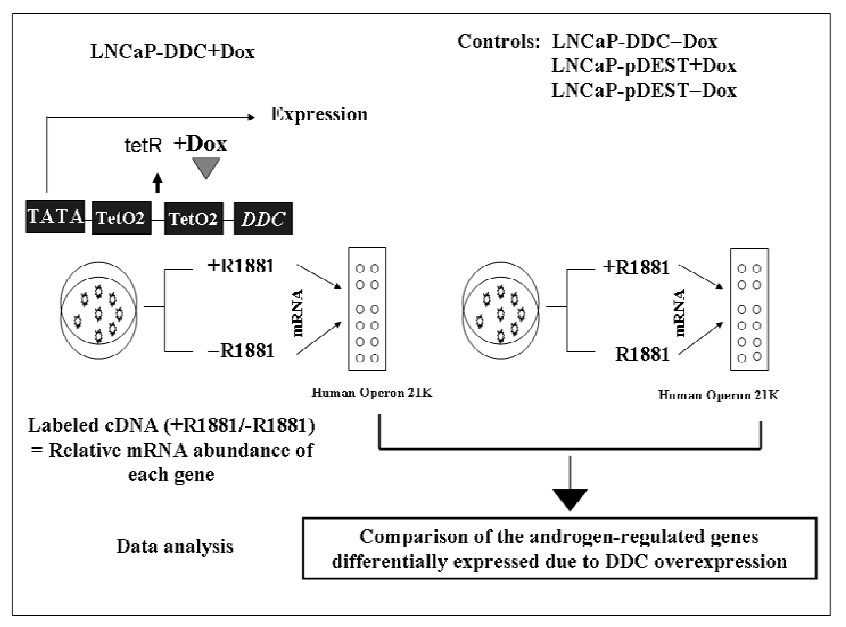

\section{Figure 2}

Microarray analysis of DDC-regulated genes. Experimental outline of microarray studies to identify DDC downstream targets using LNCaP-DDC stable and control LNCaP-pDEST cells. In the presence of Dox (grey triangle, + Dox) the tetracycline Tet repressor (tetR) is released from the TetO2 sequence in the promoter of the lentiviral construct containing the DDC gene. The dissociation of the tet $R$ allows induction of transcription for the gene of interest. LNCaP-DDC and LNCaP-pDEST (vector control) cell lines were plated in medium containing $5 \%$ charcoal-stripped serum and incubated overnight. The next day, cells were treated for 48 hours under mock-induced (-Dox) and Doxinduced (+Dox) conditions, $24 \mathrm{~h}$ of which was in the presence or absence of 0.1 nM RI88I. Total RNA samples were isolated from each condition, labeled and hybridized on the microarrays. The relative mRNA abundance of each gene was calculated as a ratio between hormone-treated $(+R I 88 I)$ and hormone-untreated (- RI88I) samples. The comparison of the expression data obtained from LNCaPDDC+Dox stable cells (left) with the expression data from the three LNCaP control cells (right: LNCaP-DDC-Dox, LNCaP-pDEST- Dox, and LNCaP-pDEST+Dox) yielded the identification of genes that are androgen- and DDC-regulated.

Among the androgen-regulated genes we identified, using Venn diagram analysis, 130 genes that were androgen-regulated in LNCaP-DDC and LNCaP control cells (Figure $4 \mathrm{~A})$. The hormone induction response of these 130 genes was substantiated by the altered expression of the classically androgen-regulated genes, such as PSA, FKBP5, NKX3A, TMEPAI, KLK2, ODC1, and TMPRSS2 (data not shown). Comparison of LNCaP-DDC and LNCaP control cells revealed a number of changes in the expression profile of these androgen-regulated genes. Out of the 130 genes, 35 were differentially regulated as shown in Table 1. Of these, 25 genes were up-regulated at least two fold and 10 were down-regulated by at least two fold with

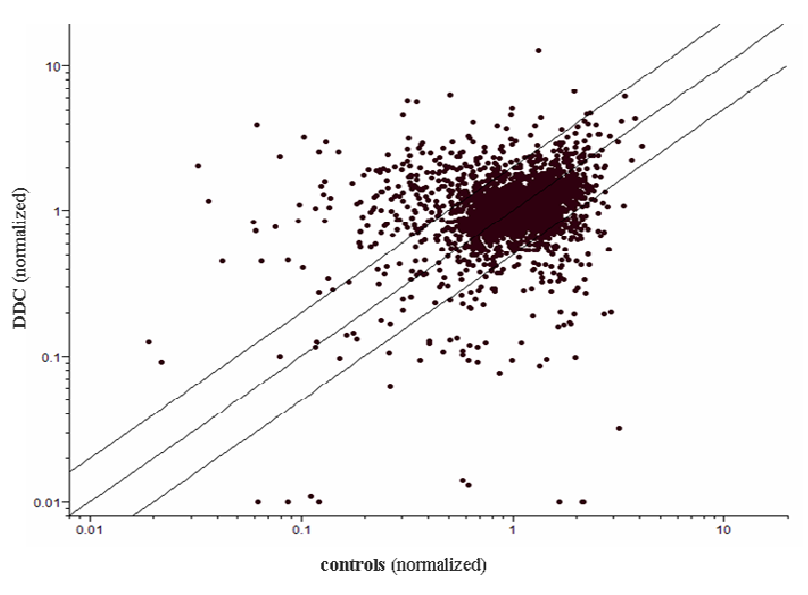

Figure 3

Scatter plot of entire gene set considered expressed ( $p$ values $=0.05$ ) in the microarray analysis. The position of each dot on the scatter plot corresponds to the normalized average signal intensity (log scale) of a single gene. The normalized average signal intensity under the DDC overexpression conditions are shown on the $x$ and $y$ axes (controls = no DDC overexpression and DDC = DDC overexpression). The middle line indicates values that represent a DDC/controls ratio of 1.0 (similar levels of expression in both cell lines). The outer lines represent a DDC/controls ratio of 2.0 (upper line; 2 -fold greater expression in DDC compared to controls) and of 0.5 (lower line; 2 -fold greater expression in controls compared to DDC).

DDC overexpression. In particular, among the set of 35 genes, we could identify four different responses to hormone treatment and DDC overexpression: $i) 2$ genes were hormone and DDC up-regulated ii) 4 genes were hormone and DDC down-regulated iii) 23 genes were hormone down-regulated in control cells and hormone upregulated in DDC overexpressing cells iv) 6 genes were hormone up-regulated in control cells and hormone down-regulated in DDC overexpressing cells (Figure 4B).

Gene ontology classification of these 35 differentially expressed genes was performed by using GeneBank accession number, Operon ID, and annotation tools database available on-line $[28,29]$. The gene sets were classified according to their putative main molecular function. While the list of 35 genes contained 15 unclassified transcripts, of the remaining 20, ontological molecular function analyses revealed signal transducer, binding, and catalytic activity as the predominant divergences between DDC overexpressing cells and controls (Table 1). Gene ontology classifications with overlapping gene lists were combined. The signal transducer classification defines those transcripts that mediate the transfer of a signal from the outside to the inside of a cell by a means other than 
Table I: Differentially expressed genes in response to DDC overexpression*. The genes shown here are those whose expressions are increased $(\geq 2)$ or decreased $(\leq-2)$.

\begin{tabular}{|c|c|c|}
\hline Genbank Acc & Gene Symbol \& Name & DDC/CTRLs \\
\hline \multicolumn{3}{|l|}{ Binding } \\
\hline $\mathrm{BC} 016658$ & E2F7; E2F transcription factor 7 & -13.60 \\
\hline$\underline{\mathrm{AK} 024500}$ & $\begin{array}{c}\text { MICALI; microtubule associated } \\
\text { monoxygenase }\end{array}$ & +7.92 \\
\hline $\mathrm{BC} 009212$ & MTAI; metastasis associated I & +9.50 \\
\hline NM 032943 & SYTL2; synaptotagmin-like 2 & -2.02 \\
\hline AK027I28 & ZNF277; zinc finger protein 277 & -3.88 \\
\hline AK054916 & ZNF333; zinc finger protein 333 & +4.67 \\
\hline AK056666 & ZNF488; zinc finger protein 488 & +6.76 \\
\hline \multicolumn{3}{|c|}{ Binding and catalytic activity } \\
\hline NM 019885 & $\begin{array}{l}\text { CYP26B I; cytochrome P450, family } \\
26 \text {, subfamily B, polypeptide I }\end{array}$ & +4.29 \\
\hline NM 022819 & PLA2G2F; phospholipase A2, group & +30.10 \\
\hline NM 004613 & TGM2; transglutaminase 2 & +2.10 \\
\hline$\overline{\mathrm{AKO} 022930}$ & $\begin{array}{c}\text { YMEILI; YMEI-like I (S. } \\
\text { cerevisiae) }\end{array}$ & +21.40 \\
\hline \multicolumn{3}{|c|}{ Binding and signal transducer activity } \\
\hline NM 000796 & DRD3; dopamine receptor $\mathrm{D} 3$ & -4.28 \\
\hline$\underline{\text { U92285 }}$ & $\begin{array}{l}\text { GABRE;Gamma-aminobutyric acid } \\
\text { (GABA) A receptor, epsilon }\end{array}$ & +10.02 \\
\hline NM 004532 & MUC4; mucin 4, tracheobronchial & -6.39 \\
\hline AF070577 & $\begin{array}{l}\text { OPCML; opioid binding protein/cell } \\
\text { adhesion molecule-like }\end{array}$ & -3.87 \\
\hline NM 003728 & $\begin{array}{c}\text { UNC5C; unc-5 homolog } C(C . \\
\text { elegans })\end{array}$ & +18.48 \\
\hline \multicolumn{3}{|l|}{ Catalytic activity } \\
\hline AK055136 & $\begin{array}{l}\text { C2orfI I; chromosome } 2 \text { open } \\
\text { reading frame II }\end{array}$ & +5.79 \\
\hline AK054688 & PON2; paraoxonase 2 & +6.99 \\
\hline \multicolumn{3}{|c|}{ Signal transducer activity } \\
\hline NM 005290 & $\begin{array}{c}\text { GPR I5; G protein-coupled receptor } \\
15\end{array}$ & +7.47 \\
\hline AK026202 & $\begin{array}{l}\text { PTGDR; prostaglandin D2 } \\
\text { receptor (DP) }\end{array}$ & +5.26 \\
\hline \multicolumn{3}{|l|}{ Unclassified } \\
\hline$\underline{A L I 10152}$ & $\begin{array}{c}\text { CD I09; CD I09 antigen (Gov platelet } \\
\text { alloantigens) }\end{array}$ & +6.20 \\
\hline NM 006408 & $\begin{array}{c}\text { AGR2; anterior gradient } 2 \text { homolog } \\
\text { (Xenopus laevis) }\end{array}$ & -5.31 \\
\hline NM 004312 & ARR3; arrestin 3, retinal (X-arrestin) & -8.08 \\
\hline NM 032149 & $\begin{array}{l}\text { C4orfI 7; chromosome } 4 \text { open } \\
\text { reading frame } 17\end{array}$ & -6.81 \\
\hline AK024536 & $\begin{array}{c}\text { CADPS; Ca2+-dependent secretion } \\
\text { activator }\end{array}$ & +8.45 \\
\hline$\underline{\mathrm{BC} 015117}$ & $D E P D C 4 ;$ DEP domain containing 4 & +7.83 \\
\hline AK057372 & $\begin{array}{c}\text { FLJ32810; hypothetical protein } \\
\text { FLJ32810 }\end{array}$ & -14.32 \\
\hline AF305616 & $\begin{array}{c}\text { TMEPAl; transmembrane, } \\
\text { prostate androgen induced } \\
\text { RNA }\end{array}$ & +2.06 \\
\hline AK025272 & Unkown & +15.27 \\
\hline AK021730 & Unkown & +31.81 \\
\hline $\mathrm{AFI} 30053$ & Unkown & +23.33 \\
\hline AL080106 & Unkown & +4.04 \\
\hline AK021569 & Unkown & +16.22 \\
\hline$\overline{\mathrm{AK} 001133}$ & Unkown & +7.59 \\
\hline AK055083 & Unkown & +6.91 \\
\hline
\end{tabular}

*Bold indicated genes investigated further by RT-PCR the introduction of a signal molecule itself into the cell. The binding activity category defines those transcripts encoding for proteins capable of selective, often stoichiometric, interaction with one or more specific sites on another protein. The catalytic activity group refers to those proteins able to perform the catalysis of a biochemical reaction. Further annotation analysis of the transcripts involved in signal transduction, subclassified four genes into the G-protein-coupled receptors (GPCRs) signaling pathway (DRD3, PTGDR, GPR15, and GABRE). Interestingly, we found a 4.3-fold down-regulation of the DRD3 gene in DDC overexpressing cells when compared with controls. The DRD3 gene encodes the D3 subtype dopamine receptor which binds dopamine, one of the enzymatic products of DDC [30]. The D3 receptor, along with the other GPCRs, are known to modulate a plethora of signal transduction pathways that can cross-talk with known AR activation pathways [4]. Among the genes upregulated by DDC overexpression, there was a well established androgen regulated TMEPAI gene [31,32] (Table $1)$. Another gene up-regulated by DDC overexpression was TGM2, which belongs to the transglutaminase (hTGP) enzyme family (EC 2.3.2.13) [33]. Interestingly, the expression of one of these family members, prostate transglutaminase enzyme (TGM4), has been shown to be androgen-regulated [34]. SYTL2 was among the androgen down-regulated genes, and has been previously shown to be differentially regulated by $\mathrm{AR}$ reduction in prostate cancer cells [35]. Overall, our results indicated that 35 genes were differentially expressed after induced overexpression of DDC in LNCaP cells, including genes known to be up- or down-regulated by AR.

Verification of microarray results by quantitative $R T-P C R$ To verify the results of our microarray analyses, we selected seven representative genes from the list in Table 1 and determined their expression profiles by quantitative real-time RT-PCR. TMEPAI, SYTL2, TGM2, DRD3, and PTGDR were chosen because of the above consideration, whereas UNC5C and YME1L1 genes were selected based on the large magnitude of change (Table 1) and GAPDH was used as an endogenous control. The same RNA samples used for the microarray hybridization were examined. For simplicity we did not consider the mockinduced (-Dox) samples, but compared the RNA extracted from LNCaP-DDC Dox-induced cells (+Dox) versus the RNA extracted from the empty vector LNCaP-pDEST Doxinduced cells (+Dox). Although the magnitudes of up-or down-regulation of the TMEPAI, SYTL2, TGM2, DRD3, YME1L1 and PTGDR genes in the array analysis were different than that observed by real time RT-PCR, there was a similar trend in the changes with respect to both R1881 treatment and DDC overexpression (Table 2). A constant level of GAPDH was observed. Unfortunately no voluble template was obtained for the UNC5C gene. Overall, the 


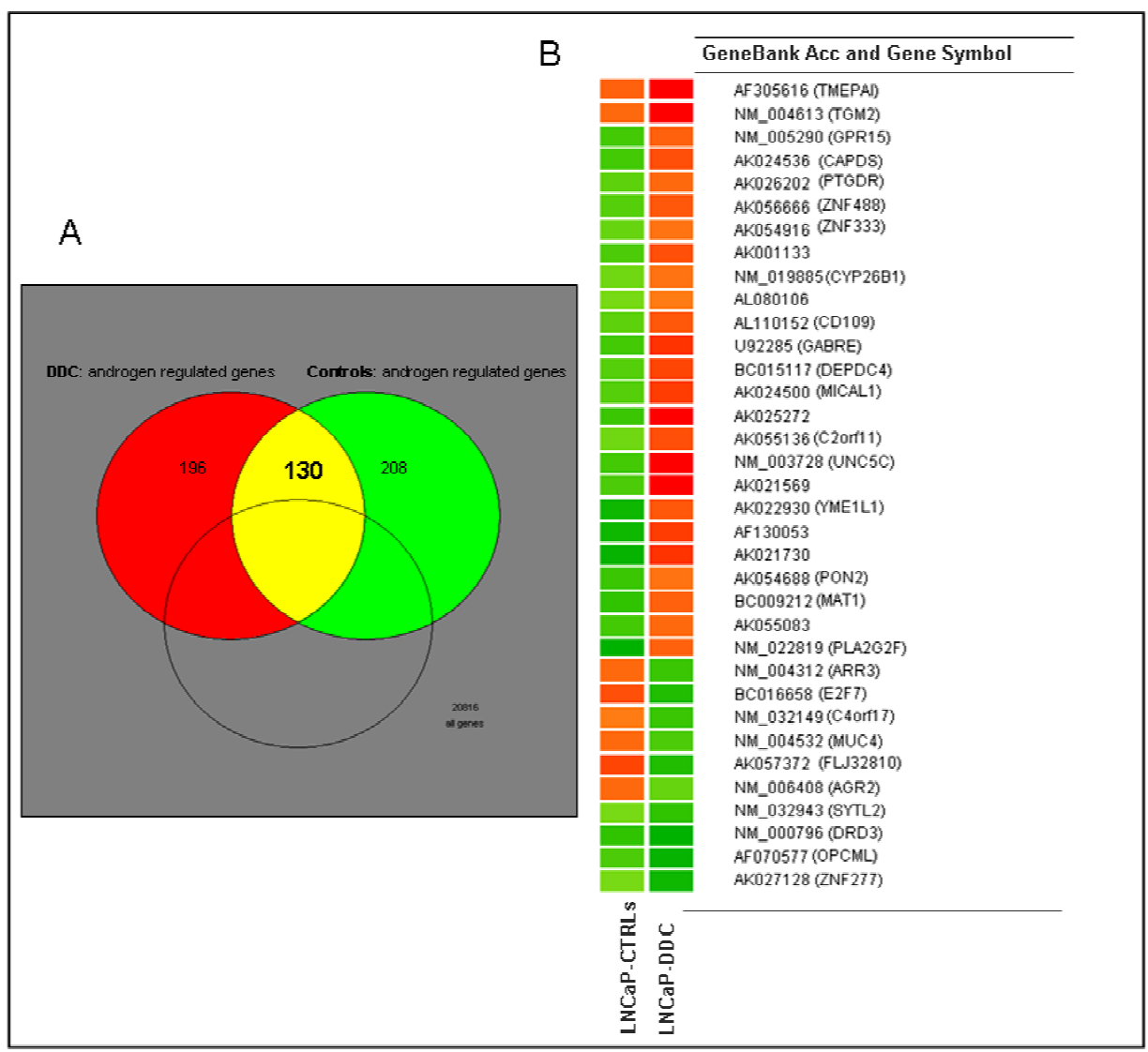

Figure 4

Androgen-regulated and DDC-regulated genes. A) A Venn diagram analysis showing in yellow, the genes (I30) with two fold induction in response to RI88I treatment in DDC overexpressing and control cells. The genes up- and down-regulated only in DDC overexpressing cells are represented in red (DDC; left) and the genes up- and down-regulated only in the control cells are represented in the green (controls; right). B) Reported here are 35 androgen-regulated genes differentially expressed at least 2-fold in DDC overexpressing cells (LNCaP-DDC) compared with the controls cells (LNCaP-CTRLs). The colors represent the ratio of gene expression levels in each cell line after RI88I treatment (red = hormone up-regulated and green $=$ hormone down-regulated).

above results verify the data observed in our microarray studies.

\section{Discussion}

Our laboratory has shown that DDC is a coactivator of AR [18] and a neuroendocrine marker of prostate cancer that increases in expression during hormone-ablation therapy and after progression to $\mathrm{AI}$ [22]. Coregulator proteins play a crucial role in modulating transactivation of AR and consequently may be important in regulating aberrant activity of AR during prostate cancer progression. In this study, we explored the effect of overexpression of DDC on the gene expression profile of an androgen-dependent prostate cancer cell line. We employed a tetracycline-regulated system to inducibly overexpress DDC and screen for potential downstream target genes in LNCaP cells using an oligonucleotide array with $21 \mathrm{~K}$ individual human genes. In particular, we first selected a list of genes that were androgen-regulated regardless of DDC status. To this end, in both DDC overexpressing and control cells, we selected all the genes that were significantly expressed $(p \leq$ 0.05 ) and which displayed at least a 2 fold increased or decreased expression due to hormone treatment ( \pm R1881). Our interest was then focused on the identification of those genes that were differentially regulated by DDC overexpression.

Comparison of DDC overexpressing cells (LNCaP-DDC) versus controls cells revealed a number of changes in the expression of androgen-regulated transcripts encoding proteins with a variety of molecular functions, including signal transduction, binding and catalytic activities. 
Although the classically androgen-regulated gene, prostate-specific antigen (PSA), was on the chip and was found in the hormone up-regulated genes group, it did not show any significant difference in gene expression levels when DDC was overexpressed. This may be due to the possibility that PSA expression is not DDC-specific or long-term (> 2 days) overexpression of DDC, may be required to increase PSA expression. This was not entirely unexpected since most classical coactivators, such as SRC/p160 family members, have not been reported to increase androgeninduced expression of endogenous PSA in LNCaP cells.

In this study, 25 up-regulated and 10 down-regulated genes were identified in DDC overexpressing cells compared with control cells (Table 1). Real-time RT-PCR confirmed and validated the microarray gene expression data. The difference in magnitude observed between microarray findings and quantitative RT-PCR is likely due to different technique efficiency and/or primers specificity (Table 2). Among the genes that were hormone and DDC up-regulated, there was a well established androgen regulated gene,TMEPAI [31]. In a previous study, evaluation of TMEPAI (also referred to as PMEPA1) expression in LNCaP cells demonstrated induction by androgen in a time- and dose-dependent manner. Interestingly, the authors also showed that TMEPAI was overexpressed in AI tumors when compared with androgen sensitive tumors [31]. Another gene found to be hormone and DDC upregulated is the TGM2 gene, which belongs to the transglutaminases (TGases) family (EC 2.3.2.13) [33]. The transglutaminases are calcium-dependent enzymes catalyzing the post-translational cross-linking of proteins. Even though no direct androgen regulation has been reported for the TGM2 gene, another transglutaminase enzyme (TGM4) has been found to be androgen regulated in human prostate cancer cell lines [34]. Androgen and DDC induced expression of TMEPAI and TGM2 may represent direct evidence of the androgen-dependent co-activation function of DDC on AR.
Among the hormone and DDC down-regulated genes was the SYTL2 gene, which was previously shown to be positively regulated by AR reduction in androgen-ablated prostate cancer cells [35]. In particular, a 2 fold up-regulation of the SYTL2 gene was found after $48 \mathrm{~h}$ reduction of AR [35], demonstrating that SYTL2 is normally an androgen-repressed gene. In our study, overexpression of DDC further reduced the expression of SYTL2, suggesting that this AR-binding protein may also augment the repressive transcriptional function of AR. The SYTL2 gene encodes for the vesicular transport protein synaptotagmin 2, which regulates exocytosis of synaptic vesicles and appears to serve as a calcium sensor to trigger neurotransmitter release [36]. A possible explanation of this finding could be related to the increased synthesis of neurotransmitters produced by DDC inside the cell, and subsequent negative feedback on these vesicular transporter related proteins.

Among the genes differentially regulated in DDC overexpressing cells, were four genes encoding GPCR proteins (DRD3, PTGDR, GPR15, and GABRE). The GPCRs share significant structural homology $[37,38]$ and are known to modulate numerous of signal transduction pathways that can cross-talk with known AR activation pathways [4]. A general model for GPCR activity has been postulated where GPCRs are in equilibrium between active and inactive states, and that interaction with a GPCR agonist, stabilizes a conformational change in these receptors which in turn promote signal generation inside the cell [39]. Recently, it has been shown that transition of prostate cancer to the AI stage is associated with increased expression of GPCRs [40-42]. Furthermore, in vitro stimulation of endogenous GPCRs (e.g. LPA, B1R) induces mitogenic signaling and growth of AI prostate cancer [42-44]. Prostate cancers also express elevated levels of GPCR ligands, which may contribute to progression of disease $[40,41,45]$. Therapies targeting GPCRs represent the single largest drug class [46], suggesting that they may be effective in limiting pathologic growth of the prostate.

Table 2: Confirmation of microarray findings by real-time RT-PCR*

\begin{tabular}{lcccccc}
\hline & \multicolumn{3}{c}{ RI88I \pm} & \multicolumn{2}{c}{ RI88I \pm} \\
\cline { 2 - 4 } Symbol & ARRAY DDC & ARRAY controls & RT-PCR DDC & RT-PCR control & ARRAY DDC/controls & RT-PCR DDC/control \\
\hline TGM2 & $\mathbf{4 . 7}$ & $\mathbf{2 . 2}$ & $\mathbf{3 6 . 7}$ & $\mathbf{2 5 . 2}$ & +2.1 & +1.5 \\
TMEPAI & $\mathbf{4 . 8}$ & $\mathbf{2 . 3}$ & $\mathbf{1 7 . 8}$ & $\mathbf{1 0 . 6}$ & +2.1 & +1.7 \\
PTGDR & $\mathbf{2 . 2}$ & 0.4 & $\mathbf{1 . 5}$ & 0.5 & +5.3 & +3.0 \\
YMEILI & $\mathbf{2 . 6}$ & 0.1 & $\mathbf{1 . 3}$ & 0.8 & -2.0 & +2.5 \\
SYTL2 & 0.3 & 0.5 & 0.2 & 0.3 & -4.3 & -1.5 \\
DRD3 & 0.1 & 0.3 & 0.5 & 0.9 & -1.8 & \\
\hline
\end{tabular}

* In bold are represented the fold changes of hormone up-regulated genes and in italic the fold changes of hormone down-regulated genes, after RI88I treatment. The symbols $+/$ - indicate the fold induction (+) or repression (-) due to DDC overexpression. 
Table 3: Primers for real time RT-PCR analysis

\begin{tabular}{lcc}
\hline Gene & Forward primer & Reverse primer \\
\hline TMEPAI & TGCCGTTCCATCCTGGTT & AGACAGTGACAAGGCTAGAGAAAGC \\
YMEILI & GAGCTTGGACACAACCGATAACT & CCGCAGTGTACAGGGATTGA \\
SYTL2 & TCTGCCTTGAGAAAACAAACAGTT & GCCAGTGGGTGGCACTAAAA \\
UNC5C & GGCCGTCCAGGTGAATCA & TGCATTCTTGCCTGTGAAGTG \\
TGM2 & TCTCTGGGCCTTTGTTTCCTT & GATCCTTGGAGATGAGCTGGTT \\
PTGDR & TCAGGACTCCAAGGTGCAAAG & TCTGGCTGGAGGTCTTGAGATC \\
DRD3 & GAATTCCCTGAGTCCCACCAT & GATGCTGAGTTTCGAACTTC \\
GAPDH & GAAGGTGAAGGTCGGAGT & GAAGTGGTGATGGGATTTC \\
\hline
\end{tabular}

Further studies are required to establish any relationships between prostate cancer progression and increased expression levels of PTGDR, GPR15, and GABRE genes. In contrast, the DRD3 gene was found to be down-regulated in DDC overexpressing cells when compared with control cells. The DRD3 gene encodes the D3 subtype dopamine receptor for which the DDC neurotransmitter product, dopamine, is an agonist. D3 receptor is classified as a member of the D2-like dopamine receptor family, which also includes the D2 and D4 dopamine receptor subtypes $[47,48]$. Interestingly, it has been shown that D2-like receptors can modulate many signal transduction pathways (e.g. MAPK, PKA, PKC) [49-51] that are also known to stimulate AR activation $[4,52,53]$. Altered regulation of this receptor in prostate cancer cells could lead to indirect activation of the AR signaling pathway. Since D2-like receptors can mediate inhibition of CAMP and PKA signaling [51], one can speculate that in the presence of dopamine, decreased expression of the D3 receptor subtype could reduce its inhibitory effect on the cAMP and PKA pathways when DDC is overexpressed. This may result in high level activation of PKA signaling that can enhance AR activity [4]. Overall, the altered expression of GPCRs by DDC may result in increased mitogenesis and growth of prostate tumors.

\section{Conclusion}

This study demonstrates that overexpression of the DDC gene in the LNCaP cells leads to differential expression of a total of 35 genes. More detailed studies examining the association between the AR-DDC interaction and these genes are necessary to better understand the functional relationships. Potentially all these putative hormone-regulated genes are directly or indirectly downstream targets of DDC and they may be important for orchestration of molecular changes that are responsible for prostate cancer progression. Also since DDC expression increases with long-term neo-adjuvant hormone therapy ( $>6$ months) and in metastatic tumors that have progressed to the AI phenotype [22], future studies could utilize castrated (hormone-deprived) mice in the LNCaP xenograft model as an in vivo experimental system for monitoring the potential effects of DDC on the expression profile of genes associated with growth, regression, and progression to AI.

\section{Methods \\ LNCaP cells expressing tetracycline-inducible DDC}

LNCaP cells stably expressing tetracycline-inducible DDC (LNCaP-DDC) were generated using ViraPower T-REx Lentiviral Expression System and Gateway Technology vectors, according to the manufacturer's protocol (Invitrogen) (Wafa LA, 2007 manuscript in preparation). Briefly, 3 $\mu \mathrm{g}$ of each lentiviral vector, pLenti4/TO/V5-DEST carrying the DDC gene or the empty vector pLenti4/TO/V5-DEST and the pLenti6/TR containing the TetR gene, together with $9 \mu \mathrm{g}$ of the ViraPower packaging mix, were transfected into 293T cells, using Lipofectamine 2000 reagent (Invitrogen, Carlsbad, CA). The DNA- Lipofectamine 2000 complexes diluted in Opti-MEM I Medium (Gibco$\mathrm{BRL}$ ) were allowed to form for $20 \mathrm{~min}$ at room temperature before addition to $293 \mathrm{~T}$ cells. Cells were maintained for 24 hours at $37^{\circ} \mathrm{C}$ and $5 \% \mathrm{CO}_{2}$ before removing the media containing the DNA-Lipofectamine 2000 complexes and replacing with DMEM media (10\% FBS, $2 \mathrm{mM}$ L-glutamine, $0.1 \mathrm{mM}$ MEM Non-Essential Amino Acids, $1 \%$ penicillin/streptomycin, and $1 \mathrm{mM}$ MEM Sodium Pyruvate).

Resulting retroviral particles were harvested by removing medium 72 hours after transfection and used to generate a stably co-transduced LNCaP cell lines. Two cell lines were created: the LNCaP-DDC line, which expresses tetracycline-inducible DDC, and the LNCaP-pDEST line, which contains the empty vector control and the tet $R$ gene. To induce tetracycline-regulated DDC expression 1 $\mu \mathrm{g} / \mathrm{ml}$ of doxycycline hyclate (Dox) (Sigma-Aldrich) was added to the cell culture media.

\section{RNA isolation and expression profiling}

LNCaP-DDC, and LNCaP-pDEST cell lines were plated in 10 -cm plates $\left(2 \times 10^{6}\right.$ per plate $)$ in RPMI 1640 containing 5\% charcoal-stripped serum (CSS; HyClone, VWR, West Chester, PA). When the cells reached 60\% confluence, they were seeded in presence of $1 \mu \mathrm{g} / \mathrm{ml}$ of Dox (Dox- 
induced) or in the absence of Dox (mock-induced). After 24 hours the cells were stimulated with or without $0.1 \mathrm{nM}$ of synthetic androgen ( \pm R1881) for an additional 24 hours. Total RNA was extracted using Trizol reagent by following the manufacturer's instructions (Invitrogen). Total RNA from each hormone-treated sample $(+\mathrm{R} 1881)$ was compared with that of hormone-untreated sample ($\mathrm{R} 1881$ ) on the same microarray slide. Two independent biological replicates were assayed for each sample and a dye swap was performed to account for dye bias. Microarrays of 21,521 (70-mer) human oligos representing 21,521 genes (Operon Technologies, Inc., Alameda, CA) printed on aminosilane coated microarray slides (Matrix Technologies; Hudson, NH) were supplied by the Array Facility of The Prostate Centre at Vancouver General Hospital. Microarrays were hybridized with $10 \mu \mathrm{g}$ of total RNA from duplicate samples of LNCaP-DDC or LNCaP-pDEST cells treated with or without $( \pm)$ Dox, and with or without $( \pm)$ R1881, using the 3DNA Array 350 ${ }^{\mathrm{TM}}$ Expression Array Detection Kit and according to the manufacturer's instructions (Genisphere, Hatfield, PA) (Figure 2). The arrays were immediately scanned on a Scan Array Express Microarray Scanner (Perkin Elmer). Signal quality and quantity were assessed using ImaGene 7.0 software (BioDiscovery, San Diego, CA).

\section{Western blot analysis}

The DDC antibody was purchased from Chemicon (Chemicon Inc., Temecula, CA) and the polyclonal antibody to actin was obtained from Sigma (Sigma Chemical Co., St. Louis, MO). LNCaP-DDC and LNCaP-pDEST cells were plated in six-well plates $\left(3 \times 10^{5}\right.$ per well $)$, treated with Dox as described above and immunoblotted as previously reported [18]. Total cell protein $(50 \mu \mathrm{g})$, measured by $\mathrm{BCA}^{\mathrm{TM}}$ Protein Assay (PIRCE, Rockford, IL), was used for immunoblotting. Band intensity was quantified using a Bio-Rad Gel Doc 2000 software (Bio-Rad Laboratories, USA).

\section{Bioinformatics analysis}

Raw signal data files obtained with ImaGene 7.0 software were subsequently analyzed on GeneSpring 7.2 software (Silicon Genetics, Redwood City, CA) for profiling significant changes in gene expression. The fluorescent signal ratios (+R1881/-R1881) were subjected to Lowess normalization with background correction. Experimental error was based on replicated dye pair values. Comparison analysis of the gene expression data from LNCaP-DDC+Dox cells, and LNCaP-DDC-Dox, LNCaP-pDEST-Dox, and LNCaPpDEST+Dox cells, treated with or without R1881, was conducted to first identify androgen-regulated genes in all experimental conditions, and then the differentially regulated genes due to DDC overexpression.

Only genes with a $p$ value of $\leq 0.05$ in at least one out of two conditions were analyzed further. Data was transformed to $\log$ ratio $\left(\log _{10}\right)$ for display and analysis. All genes showing a normalized expression value $\geq 2$ or $\leq 0.5$ were classified as androgen up- or down-regulated, respectively. Genes showing a normalized expression value between 0.5 - and 2- were classified as unchanged and not considered further. Lists of androgen-regulated genes (both up-regulated and down-regulated) were created for each of the cell lines and were compared by Venn diagram analysis. Genes were considered differentially expressed as a result of DDC overexpression if normalized values from induced LNCaP-DDC cells were at least 2-fold greater or 2-fold less than those from the control cells (LNCaP-DDC-Dox, LNCaP-pDEST- Dox, and LNCaPpDEST+Dox). Functional classifications were based on gene ontology (GO) annotation obtained through the GeneTools database $[28,29]$.

\section{Real-time quantitative RT-PCR and semiquantitative RT- PCR}

Complementary DNA (cDNA) for real time PCR and semiquantitative RT-PCR was made using $2 \mu \mathrm{g}$ of total RNA treated with RNase-free DNase according to the manufacturer's instructions (Promega). First-strand cDNA was synthesized using random hexamers (Perkin-Elmer Applied Biosystems, Branchburg, NJ) with 20U of Moloneymurine leukemia virus reverse transcriptase, M-MLV (Invitrogen). The ABI PRISM 7700 Sequence Detection System (PerkinElmer Applied Biosystems, Foster City, CA) was used for real time monitoring of PCR amplification of CDNA. The forward and reverse primers used for the real time RT-PCR are listed in Table 3. All primers were selected by PRIMER EXPRESS v. 3 software and were commercially synthesized by Integrated DNA Technologies laboratories (IDT, Coralville IA). A SYBR green PCR kit was used following the manufacturer's instructions and the analyses were performed in triplicate (Invitrogen). In brief, RT-PCR amplification mixtures $(25 \mu \mathrm{l})$ containing $25 \mathrm{ng}$ template cDNA, 2x SYBR Green I Master Mix buffer $(12.5 \mu \mathrm{l})$, and $300 \mathrm{nM}$ forward and reverse primer was prepared. Target mRNA values were normalized using GAPDH mRNA as an internal control. A comparative threshold cycle (Ct) was used to determine gene expression relative to a calibrator. For each sample, the $\mathrm{Ct}$ values were calculated using the formula $\Delta \mathrm{C}_{\mathrm{T}}=\mathrm{C}_{\mathrm{t} \text { sample }} \mathrm{C}_{\mathrm{t} \text { GAPDH}}$. To determine relative expression levels, the following formula was used $\Delta \Delta \mathrm{C}_{\mathrm{T}}=\Delta \mathrm{C}_{\mathrm{T} \text { sample }}{ }^{-} \Delta \mathrm{C}_{\mathrm{T}}$ calibrator and the value used to indicate relative gene expression was calculated using the formula $2-\Delta \Delta C T$. Primers for the semiquantitative PCR were synthesized by Integrated DNA Technologies laboratories (IDT, Coralville IA); DDC, sense 5'- ACA CCA TGA ACG CAA GTG AA-3' and antisense 5'- CAC CCC AGG CAT GAT TAT CT-3'. The PCR products (209 bp) were resolved by electrophoresis using $1.5 \%$ agarose gels containing ethidium bromide.

\section{Competing interests}

The author(s) declare that they have no competing interests. 


\section{Authors' contributions}

K.M. performed the study and drafted the manuscript; L.A.W. helped to design the study and to draft the manuscript; H.C. helped to perform the study; G.N. critically commented on the drafted manuscript; C.C.N participated in the design of the study and critically commented on the drafted manuscript; P.S.R. provided overall direction for the project and revised the final version of the manuscript; G.N., C.C.N., and P.S.R obtained funding for the project. All authors read and approved the final manuscript.

\section{Acknowledgements}

We thank Robert Bell for assistance with gene expression data analysis and Anne Haegert for technical assistance with the microarray experiments. This work was supported by the Canadian Cancer Society and the National Cancer Institute of Canada (NClC), and in part by funds from AIRC (Associazione Italiana per la Ricerca sul Cancro) Regional Grant to G.N.

\section{References}

I. Jemal A, Murray T, Ward E, Samuels A, Tiwari RC, Ghafoor A, Feuer EJ, Thun MJ: Cancer statistics, 2005. CA Cancer J Clin 2005, 55(1): 10-30.

2. Klotz L: Hormone therapy for patients with prostate carcinoma. Cancer 2000, 88(I 2 Suppl):3009-30I4.

3. Long RJ, Roberts KP, Wilson MJ, Ercole CJ, Pryor JL: Prostate cancer: a clinical and basic science review. J Androl 1997, I8(I):I5-20.

4. Feldman BJ, Feldman D: The development of androgen-independent prostate cancer. Nat Rev Cancer 200I, I(I):34-45.

5. Brinkmann AO, Blok LJ, de Ruiter PE, Doesburg P, Steketee K, Berrevoets CA, Trapman J: Mechanisms of androgen receptor activation and function. J Steroid Biochem Mol Biol 1999, 69:307-3/3.

6. Alen P, Claessens F, Verhoeven G, Rombauts W, Peeters B: The androgen receptor amino-terminal domain plays a key role in pl60 coactivator-stimulated gene transcription. Mol Cell Biol 1999, 19(9):6085-6097.

7. McKenna NJ, O'Malley BW: Combinatorial control of gene expression by nuclear receptors and coregulators. Cell 2002, 108(4):465-474.

8. Chen CD, Welsbie DS, Tran C, Baek SH, Chen R, Vessella R, Rosenfeld MG, Sawyers CL: Molecular determinants of resistance to antiandrogen therapy. Nat Med 2004, 10(I):33-39.

9. Koivisto P, Kononen J, Palmberg C, Tammela T, Hyytinen E, Isola J, Trapman J, Cleutjens K, Noordzij A, Visakorpi T, Kallioniemi OP: Androgen receptor gene amplification: a possible molecular mechanism for androgen deprivation therapy failure in prostate cancer. Cancer Res 1997, 57(2):314-319.

10. Miyamoto H, Yeh S, Wilding G, Chang C: Promotion of agonist activity of antiandrogens by the androgen receptor coactivator, ARA70, in human prostate cancer DUI 45 cells. Proc Natl Acad Sci U S A 1998, 95(1 3):7379-7384.

II. Janne OA, Moilanen AM, Poukka H, Rouleau N, Karvonen U, Kotaja $\mathrm{N}$, Hakli M, Palvimo Jj: Androgen-receptor-interacting nuclear proteins. Biochem Soc Trans 2000, 28(4):40I-405.

12. Ngan ES, Hashimoto Y, Ma ZQ, Tsai MJ, Tsai SY: Overexpression of Cdc25B, an androgen receptor coactivator, in prostate cancer. Oncogene 2003, 22(5):734-739.

13. Fujimoto N, Yeh S, Kang HY, Inui S, Chang HC, Mizokami A, Chang $\mathrm{C}$ : Cloning and characterization of androgen receptor coactivator, ARA55, in human prostate. J Biol Chem 1999, 274(I2):83|6-832I.

14. Gregory CW, He B, Johnson RT, Ford OH, Mohler JL, French FS, Wilson EM: A mechanism for androgen receptor-mediated prostate cancer recurrence after androgen deprivation therapy. Cancer Res 200I, 6I(II):43I5-43I9.

15. Debes JD, Sebo TJ, Lohse CM, Murphy LM, Haugen DA, Tindall DJ: p300 in prostate cancer proliferation and progression. Cancer Res 2003, 63(22):7638-7640.
16. Comuzzi B, Lambrinidis L, Rogatsch H, Godoy-Tundidor S, Knezevic N, Krhen I, Marekovic Z, Bartsch G, Klocker H, Hobisch A, Culig Z: The transcriptional co-activator cAMP response elementbinding protein-binding protein is expressed in prostate cancer and enhances androgen- and anti-androgen-induced androgen receptor function. Am J Pathol 2003, I62(I):233-24I.

17. Scher Hl, Sawyers CL: Biology of progressive, castration-resistant prostate cancer: directed therapies targeting the androgen-receptor signaling axis. J Clin Oncol 2005, 23(32):8253-826I.

18. Wafa LA, Cheng H, Rao MA, Nelson CC, Cox M, Hirst M, Sadowski I, Rennie PS: Isolation and identification of L-dopa decarboxylase as a protein that binds to and enhances transcriptional activity of the androgen receptor using the repressed transactivator yeast two-hybrid system. Biochem J 2003, 375(Pt 2):373-383.

19. Berry MD, Juorio AV, Li XM, Boulton AA: Aromatic L-amino acid decarboxylase: a neglected and misunderstood enzyme. Neurochem Res 1996, 2 I(9): 1075-1087.

20. Craig SP, Thai AL, Weber M, Craig IW: Localisation of the gene for human aromatic L-amino acid decarboxylase (DDC) to chromosome 7pI3-->pII by in situ hybridisation. Cytogenet Cell Genet 1992, 6 I(2): I I4-II6.

21. Zhu MY, Juorio AV: Aromatic L-amino acid decarboxylase: biological characterization and functional role. Gen Pharmacol 1995, 26(4):681-696.

22. Wafa LA, Palmer J, Fazli L, Hurtado-Coll A, Bell RH, Nelson CC, Gleave ME, Cox ME, Rennie PS: Comprehensive expression analysis of I-dopa decarboxylase and established neuroendocrine markers in neoadjuvant hormone-treated versus varying Gleason grade prostate tumors. Hum Pathol 2007, 38(I): $161-170$.

23. Schena M, Shalon D, Davis RW, Brown PO: Quantitative monitoring of gene expression patterns with a complementary DNA microarray. Science 1995, 270(5235):467-470.

24. Velasco AM, Gillis KA, Li Y, Brown EL, Sadler TM, Achilleos M, Greenberger LM, Frost $P$, Bai W, Zhang $Y$ : Identification and validation of novel androgen-regulated genes in prostate cancer. Endocrinology 2004, I 45(8):39/3-3924.

25. Zhang $Y$, Akinmade D, Hamburger AW: The ErbB3 binding protein EbpI interacts with Sin3A to repress E2FI and ARmediated transcription. Nucleic Acids Res 2005, 33(18):6024-6033.

26. Ma AH, Xia L, Desai SJ, Boucher DL, Guan Y, Shih HM, Shi XB, Devere White RW, Chen HW, Tepper CG, Kung HJ: Male Germ Cell-Associated Kinase, a Male-Specific Kinase Regulated by Androgen, Is a Coactivator of Androgen Receptor in Prostate Cancer Cells. Cancer Res 2006, 66 (17):8439-8447.

27. Yan J, Yu CT, Ozen M, Ittmann M, Tsai SY, Tsai MJ: Steroid receptor coactivator-3 and activator protein-I coordinately regulate the transcription of components of the insulin-like growth factor/AKT signaling pathway. Cancer Res 2006, 66(22): $11039-11046$.

28. Beisvag $\mathrm{V}$, Junge FK, Bergum $\mathrm{H}$, Jolsum $\mathrm{L}$, Lydersen $\mathrm{S}$, Gunther $\mathrm{CC}$, Ramampiaro H, Langaas M, Sandvik AK, Laegreid A: GeneTools-application for functional annotation and statistical hypothesis testing. BMC Bioinformatics 2006, 7:470.

29. GeneTools: [http://www.genetools.no].

30. Sokoloff P, Giros B, Martres MP, Bouthenet ML, Schwartz JC: Molecular cloning and characterization of a novel dopamine receptor (D3) as a target for neuroleptics. Nature 1990, 347(6289): | $146-15 \mid$.

3I. Xu LL, Shanmugam N, Segawa T, Sesterhenn IA, McLeod DG, Moul JW, Srivastava S: A novel androgen-regulated gene, PMEPAI, located on chromosome $20 \mathrm{q} / 3$ exhibits high level expression in prostate. Genomics 2000, 66(3):257-263.

32. Rae FK, Hooper JD, Nicol DL, Clements JA: Characterization of a novel gene, STAG I/PMEPAI, upregulated in renal cell carcinoma and other solid tumors. Mol Carcinog 200I, 32(I):44-53.

33. Wang M, Kim IG, Steinert PM, McBride OW: Assignment of the human transglutaminase 2 (TGM2) and transglutaminase 3 (TGM3) genes to chromosome 20qII.2. Genomics 1994, 23(3):72।-722.

34. Dubbink HJ, Verkaik NS, Faber PW, Trapman J, Schroder FH, Romijn JC: Tissue specific and androgen-regulated expression of human prostate-specific transglutaminase. Biochem J 1996, 315 ( Pt 3): $901-908$. 
35. Haag P, Bektic J, Bartsch G, Klocker H, Eder IE: Androgen receptor down regulation by small interference RNA induces cell growth inhibition in androgen sensitive as well as in androgen independent prostate cancer cells. J Steroid Biochem Mol Biol 2005, 96(3-4):25I-258.

36. Geppert M, Archer BT 3rd, Sudhof TC: Synaptotagmin II. A novel differentially distributed form of synaptotagmin. J Biol Chem 1991, 266(2I):13548-13552.

37. Lania AG, Mantovani G, Spada A: Mechanisms of disease: Mutations of $\mathbf{G}$ proteins and $\mathbf{G}$-protein-coupled receptors in endocrine diseases. Nat Clin Pract Endocrinol Metab 2006, 2( (12):68I-693.

38. Hollmann MW, Strumper D, Herroeder S, Durieux ME: Receptors, G proteins, and their interactions. Anesthesiology 2005, 103(5): 1066-1078.

39. Perez DM, Karnik SS: Multiple signaling states of G-proteincoupled receptors. Pharmacol Rev 2005, 57(2): 147-161.

40. Daaka $Y: \mathbf{G}$ proteins in cancer: the prostate cancer paradigm. Sci STKE 2004, 2004(2 16):re2.

41. Nelson JB, Nabulsi AA, Vogelzang NJ, Breul J, Zonnenberg BA, Daliani DD, Schulman CC, Carducci MA: Suppression of prostate cancer induced bone remodeling by the endothelin receptor $A$ antagonist atrasentan. J Urol 2003, 169(3): I I43-I I 49.

42. Taub JS, Guo R, Leeb-Lundberg LM, Madden JF, Daaka Y: Bradykinin receptor subtype I expression and function in prostate cancer. Cancer Res 2003, 63(9):2037-204I.

43. Kue PF, Taub JS, Harrington LB, Polakiewicz RD, Ullrich A, Daaka $Y$ : Lysophosphatidic acid-regulated mitogenic ERK signaling in androgen-insensitive prostate cancer PC-3 cells. Int J Cancer 2002, 102(6):572-579.

44. Sivashanmugam P, Tang L, Daaka Y: Interleukin 6 mediates the lysophosphatidic acid-regulated cross-talk between stromal and epithelial prostate cancer cells. J Biol Chem 2004, 279(20):2II54-2II59.

45. Porter AT, F ACRO, Ben-Josef E: Humoral mechanisms in prostate cancer: A role for FSH. Urol Oncol 200I, 6(4): |3|-|38.

46. Nambi P, Aiyar N: G protein-coupled receptors in drug discovery. Assay Drug Dev Technol 2003, I (2):305-3I0.

47. Civelli O, Bunzow JR, Grandy DK: Molecular diversity of the dopamine receptors. Annu Rev Pharmacol Toxicol 1993, 33:28I-307.

48. Gingrich JA, Caron MG: Recent advances in the molecular biology of dopamine receptors. Annu Rev Neurosci 1993, 16:299-321.

49. Sidhu A, Niznik HB: Coupling of dopamine receptor subtypes to multiple and diverse $\mathbf{G}$ proteins. Int J Dev Neurosci 2000, | 8(7):669-677.

50. Zanassi P, Paolillo M, Feliciello A, Avvedimento EV, Gallo V, Schinell S: cAMP-dependent protein kinase induces CAMP-response element-binding protein phosphorylation via an intracellular calcium release/ERK-dependent pathway in striatal neurons. J Biol Chem 200I, 276( I 5): I | 487-I I 495.

5I. Yan Z, Feng J, Fienberg AA, Greengard P: D(2) dopamine receptors induce mitogen-activated protein kinase and CAMP response element-binding protein phosphorylation in neurons. Proc Natl Acad Sci U S A 1999, 96(20): I |607-I I6I2.

52. Sadar MD, Hussain M, Bruchovsky N: Prostate cancer: molecular biology of early progression to androgen independence. Endocr Relat Cancer 1999, 6(4):487-502.

53. Gioeli D, Ficarro SB, Kwiek JJ, Aaronson D, Hancock M, Catling AD, White FM, Christian RE, Settlage RE, Shabanowitz J, Hunt DF, Weber MJ: Androgen receptor phosphorylation. Regulation and identification of the phosphorylation sites. J Biol Chem 2002 277(32):29304-293 I 4 .
Publish with Bio Med Central and every scientist can read your work free of charge

"BioMed Central will be the most significant development for disseminating the results of biomedical research in our lifetime. "

Sir Paul Nurse, Cancer Research UK

Your research papers will be:

- available free of charge to the entire biomedical community

- peer reviewed and published immediately upon acceptance

- cited in PubMed and archived on PubMed Central

- yours - you keep the copyright

Submit your manuscript here:

http://www.biomedcentral.com/info/publishing_adv.asp
BioMedcentral 